\title{
FULL LENGTH RESEARCH ARTICLE \\ COMPARATIVE STUDIES ON DYEING RATE MIGRATION AND WASH FASTNESS PROPERTIES OF AZO DYES DERIVED FROM 2-AMINOTHIAZOLE DERIVATIVES ON ACETATE FABRICS
}

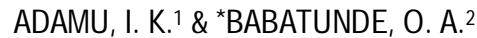 \\ ${ }^{1}$ School of Science Technology \\ Federal College of Chemical and Leather Technology \\ Samaru-Zaria, Nigeria \\ ${ }^{2}$ Department of Chemistry \\ Nigerian Defence Academy \\ Kaduna, Nigeria \\ *(Corresponding author) \\ mails4abiodun@yahoo.com
}

\begin{abstract}
Migration and diffusion properties of synthesized azo dyes from 2-aminothiazole derivatives applied on commercial grade undyed cellulose acetate (CA) and cellulose triacetate (CTA) were investigated using dyeing conditions of $2 \%$ on weight of fabric (owf), 50:1 liquor ratio and subjected to ISO3 and ISO4 standard wash fastness tests. From the studies, the wash fastness in both fabrics was found to be inversely proportional to the dye diffusion coefficient and migration properties. Tests showed some dye admixture exhibit compatibility in properties while others showed skittering effect. These observations are attributable to structural effect, degree of fabric crystallinity and surface potential effect in dye- substrate interactions.
\end{abstract}

Key words:-Migration, Diffusion, 2-Aminothiazole, Cellulose acetate, Cellulose triacetate, Skittering effect.

\section{INTRODUCTION}

Comparison of the performance of dyes on synthetic substrates for quality assessment, reproducibility of result and standardization in terms of dyeing rate, migration test, temperature range test, fastness properties etc. have continued to generate interest since 1947 when the international organization for standardization approved the standards which now appear in BS 1006 (standard method 1978). These properties are fundamental in the application of individual dyes as well as dye in admixture for improved quality, elegance and fashion (Birds \& Harris 1957; Arcoria et al. 1993).

Studies have shown that dyes with identical migration rate and fastness property could be used in admixture to produce different kinds of uniform shades without leading to skittering (Trotman 1984). Consequently this study is aimed at comparing some of these properties in a series of azo dyes from 2-aminothiazole so as to explore their application in admixture. The synthesis and spectroscopic properties of these dyes have been reported earlier (Bello et al. 1995).

\section{MATERIALS AND METHODS}

The cellulose acetate and cellulose triacetate fabrics used were of commercial grade and undyed. The dye bath was prepared by placing $2 \mathrm{~cm}^{3}$ of dispersing agent (materxil D-VL commercial grade) to assist in maintaining a stable suspension and to increase the solubility of the pigment. This was accompanied by immersion of the scored CA and CTA with dyeing continued to determine the temperature, time and also the equilibrium temperature at boiling (Bello et al. 1995).

The dye solution in dye-bath was adjusted to $\mathrm{pH}$ 4.5-5.0 with acetic acid and the goods were entered cold. Cellulose triacetate was pretreated by cold padding with $60 \%$ diethyleneglycol diacetate (DEGDA) for 1 min and rinsed. Pre-swelling of triacetate was carried to increase its affinity for disperse colours and make it possible to dye the fibre easily.

Determination of dye migration: Pieces of wetted cellulose acetate $(10 \mathrm{~cm} \times 10 \mathrm{~cm})$ and wetted cellulose triacetate $(10 \mathrm{~cm} \times 10 \mathrm{~cm})$ were each impregnated with $0.002 \mathrm{~g}$ in $2 \mathrm{~cm}^{3}$ of dye using a dropping pipette and watch glass placed over portions of the fabrics. The whole set up was dried at room temperature for $60 \mathrm{~min}$.

The watch glasses were then removed and the degree of migration assessed from the difference in areas of the fabric covered by the watch glass and the body of the fabric using gray scale rating for degree of staining (Oyewale et al. 2003). The results are shown in Table 1. The procedure for dye in admixture in the ratio 1:1 and 3:1 are shown in Table 2.

Determination of diffusion coefficient: In a thermostated dye-bath, $20 \mathrm{~cm}^{3}$ each of dye solution based on $2 \%$ on weight of cellulose acetate and cellulose triacetate fabrics (owf) in 6 dyeing test tubes of liquor ratio 50:1. Samples of wetted cellulose acetate and cellulose triacetate $(0.2 \mathrm{~g})$ were placed in the respective tubes. The dye-bath temperature was adjusted to $45^{\circ} \mathrm{C}$ and $\mathrm{pH} 4.5$ with glacial acetic acid, then steadily increased to $80{ }^{\circ} \mathrm{C}(353 \mathrm{~K})$ and maintained at this temperature.

The first 5 samples in the bath were removed at 10 mins interval for a total of 50 mins. The last sample was removed after 7 hrs of dyeing for equilibrium dyeing to be attained (Mamuda et al. 2002). Dyed samples were removed in each case, rinsed with $20 \mathrm{~cm}^{3}$ of hot and cold water respectively. Absorbance of dye liquor was measured before dyeing $\left(A_{0}\right)$, after dyeing of the first 5 samples $\left(A_{t}\right)$ and after 7 hrs $A_{s} \infty$. The amount of dye absorbed by fabric at equilibrium $A_{t}=A_{0}-A_{t}$ while the amount of dye absorbed by fabric at equilibrium $A_{f} \infty=A_{0}-A \infty$. 
The apparent diffusion coefficient (D) was obtained from the plots of $A_{t} / A_{f} \infty$ against $t_{1 / 2}$ using the relation:

$A_{t} / A_{f} \infty=1.29 \sqrt{D T}$, where $T=$ time of half dyeing (exhaustion) in seconds (Oyewale et al. 2003).

The procedure was repeated at the temperature of $100^{\circ} \mathrm{C}(373 \mathrm{~K})$ and the results presented in Table 3 . The entire procedure was repeated for dye in admixture in ratio 1:1 and 3:1 as shown in Table 2.

Determination of Wash fastness using ISO3 and ISO4 procedure: For wash fastness test No.3, Sandwiches obtained by sewing specimens measuring $4 \mathrm{~cm} \times 4 \mathrm{~cm}$ of dyed cellulose acetate and triacetate fabrics (1:1 standard depths) in contact with two adjacent white and undyed white fabrics were mechanically agitated in a wash wheel in $5 \mathrm{gl}^{-1}$ of standard soap solution at $60{ }^{\circ} \mathrm{C}$ for 30 mins and 50:1 liquor to goods ratio

After the test, the sandwiches were removed. The change of shade of the specimen and degree of staining of adjacent undyed white fabrics were assessed using standard gray scale (Mark et al. 1992; Preston 1986). Colour fastness to washing test results are shown in Table 4. The procedure was also repeated for dye in admixture in ratio1:1 and 3:1 as presented in Table 5.

RESULTS<smiles>[Y]C1C2CN(N=Nc3ccc(N([R])[R1])cc3)C(S2)C1[Y]</smiles>

Fig 1 Dye molecular Structure with substituent $X, Y, R^{1} R^{2}$ as presented in Table 1

TABLE 1: DYE STRUCTURE SUBSTITUENTS

\begin{tabular}{c|c|c|c|c}
\hline Dye & $\mathbf{X}$ & $\mathbf{Y}$ & $\mathbf{R}^{1}$ & $\mathbf{R}^{2}$ \\
\hline$A$ & $-\mathrm{CH}_{3}$ & $-\mathrm{CO}_{2} \mathrm{CH}_{2} \mathrm{CH}_{3}$ & $-\mathrm{H}$ & $\mathbf{H}$ \\
\hline$B$ & $-\mathrm{C}_{6} \mathrm{H}_{5}$ & $-\mathrm{CH}_{3}$ & $-\mathrm{CH}_{3}$ & $-\mathrm{CH}_{3}$ \\
\hline $\mathrm{C}$ & $-\mathrm{CH}_{3}$ & $-\mathrm{H}$ & $-\mathrm{CH}_{3}$ & $-\mathrm{CH}_{3}$ \\
\hline$D$ & $-\mathrm{CH}_{3}$ & $-\mathrm{CO}_{2} \mathrm{CH}_{2} \mathrm{CH}_{3}$ & $-\mathrm{CH}_{3}$ & $-\mathrm{CH}_{3}$ \\
\hline$E$ & $-\mathrm{C}_{6} \mathrm{H}_{5}$ & $-\mathrm{H}$ & $-\mathrm{CH}_{3}$ & $-\mathrm{CH}_{3}$ \\
\hline$F$ & $-\mathrm{CH}_{3}$ & $-\mathrm{H}$ & $-\mathrm{C}_{2} \mathrm{H}_{5}$ & $-\mathrm{C}_{2} \mathrm{H}_{5}$ \\
\hline$G$ & $-\mathrm{CH}_{3}$ & $-\mathrm{CO}_{2} \mathrm{CH}_{2} \mathrm{CH}_{3}$ & $-\mathrm{C}_{2} \mathrm{H}_{5}$ & $-\mathrm{C}_{2} \mathrm{H}_{5}$ \\
\hline$H$ & $-\mathrm{C}_{6} \mathrm{H}_{5}$ & $-\mathrm{CH}_{3}$ & $-\mathrm{C}_{2} \mathrm{H}_{5}$ & $-\mathrm{C}_{2} \mathrm{H}_{5}$ \\
\hline$I$ & $-\mathrm{C}_{6} \mathrm{H}_{5}$ & $-\mathrm{H}$ & $-\mathrm{C}_{2} \mathrm{H}_{5}$ & $-\mathrm{C}_{2} \mathrm{H}_{5}$ \\
\hline
\end{tabular}

The results of dyeing rate, migration and wash fastness are shown in Tables 2 and 3 respectively.

\section{DISCUSSION}

Dye migration and Diffusion coefficient: Table 2 shows the migration and diffusion coefficient of dye admixture in the substrates with ratings exhibiting similar trends in triacetate compared with the acetate. However, dyes $g$ and $h$, e and $g$ and $c$ and $i$ exhibited differential stain i.e. skittering. This is attributed to differences in molecular mass and configurational factors arising from the substituent in the dye molecular structure. For instance dye $\mathrm{g}$ has polar $-\mathrm{CO}_{2} \mathrm{C}_{2} \mathrm{H}_{5}$ substituent in the $\mathrm{Y}$-position while dye $\mathrm{h}$ has $\mathrm{H}$ in the same position. Also dye i have $\mathrm{C}_{6} \mathrm{H}_{5}$ and $-\mathrm{C}_{2} \mathrm{H}_{5}$ in $\mathrm{X}, \mathrm{R}^{1}$ and $\mathrm{R}^{2}$ positions respectively compared with less strains $\mathrm{CH}_{3}$ and $\mathrm{H}$ substituent of dye $\mathrm{C}$ in the respective positions.
Table 3 shows the gray scale rating of the dyeing properties which are characteristic of the dye and fabric types. As can be seen, dye migrations in cellulose acetate were generally better than in cellulose triacetate. This was illustrated by dye a' which shows migration 1-2 in cellulose triacetate but 2-3 in cellulose acetate indicated increase inmigration. Similarly, dye sample d shows migration rating of 2 in cellulose triacetate but 3 in cellulose acetate, also indicating better migration property. This is attributed to high degree of crystallinity and greater amorphosity of cellulose triacetate compared with cellulose acetate in which the regular packing of molecular chain is perturbed (Steven 1990). 
TABLE 2: - MIGRATION AND DIFFUSION COEFFICIENT OF DYE ADMIXTURE IN ACETATE

\begin{tabular}{|c|c|c|c|c|c|c|}
\hline Dye Admixture & \multicolumn{2}{|c|}{ Dye Migration } & \multicolumn{4}{|c|}{ Dye Diffusion coefficient $\left(\mathrm{s}^{-1}\right)$} \\
\hline $1: 1$ & CA & CTA & CA & CTA & CA & CTA \\
\hline$a \& d$ & 3 & 2 & 3-4 & 3-4 & 3-4 & $3-4$ \\
\hline$b \& c$ & 3-4 & 3 & 3-4 & 3-4 & 3-4 & 3-4 \\
\hline$h \& 1$ & 3 & 3 & 3-4 & 3-4 & 4 & 4 \\
\hline$g \& h$ & $D(3-4)$ & $\mathrm{D}(3)$ & $\mathrm{D}(0.93)$ & $\mathrm{D}(0.90)$ & $\mathrm{D}(0.92)$ & $\mathrm{D}(0.87)$ \\
\hline e \& g & $D(3-4)$ & $\mathrm{D}(3)$ & $\mathrm{D}(1.32)$ & $\mathrm{D}(1.0)$ & $\mathrm{D}(1.21)$ & $\mathrm{D}(0.93)$ \\
\hline$c \& i$ & $D(3-4)$ & $D(2-3)$ & $D(1.0)$ & $\mathrm{D}(0.82)$ & $\mathrm{D}(0.90)$ & $\mathrm{D}(0.73)$ \\
\hline 1:3 ratio & $C A$ & CTA & CA & CTA & $\mathrm{CA}$ & CTA \\
\hline$a \& d$ & 3 & 2 & 0.70 & 0.65 & 0.63 & 0.62 \\
\hline$b \& c$ & 3-4 & 3 & 1.07 & 0.80 & 0.88 & 0.72 \\
\hline$h \& i$ & 3 & 3 & 0.92 & 0.89 & 0.91 & 0.86 \\
\hline$g \& h$ & $D(3-4)$ & $\mathrm{D}(3)$ & $\mathrm{D}(0.93)$ & $\mathrm{D}(0.90)$ & $\mathrm{D}(0.92)$ & $\mathrm{D}(0.87)$ \\
\hline e \& g & $D(3-4)$ & $\mathrm{D}(3)$ & $\mathrm{D}(1.32)$ & $\mathrm{D}(1.0)$ & $\mathrm{D}(1.21)$ & $\mathrm{D}(0.93)$ \\
\hline$c \& i$ & $D(3-4)$ & $D(2-3)$ & $\mathrm{D}(1.10)$ & $\mathrm{D}(0.82)$ & $\mathrm{D}(0.90)$ & $\mathrm{D}(0.73)$ \\
\hline
\end{tabular}

$\mathrm{D}$ is differential representing average value of the two components.

Key: Change in shade: 5=Excellent, 4=Very Good, 3=Good, 2=Fair, 1= Poor.

TABLE 3: DYE MIGRATION AND DIFFUSION IN CELLULOSE ACETATE AND CELLULOSE TRIACETATE

\begin{tabular}{|c|c|c|c|c|c|c|}
\hline \multirow{3}{*}{ Dye } & \multicolumn{2}{|c|}{$\begin{array}{c}\text { Dye Migrations } \\
\end{array}$} & \multicolumn{4}{|c|}{ Dye Diffusion Coefficient $\left(\mathbf{s}^{-1}\right)$} \\
\hline & \multicolumn{2}{|c|}{ Change in Shade, Gray scale rating } & \multicolumn{2}{|c|}{$373 K$} & \multicolumn{2}{|c|}{ 353K } \\
\hline & $\mathrm{CA}$ & CTA & $\mathrm{CA}$ & CTA & $\mathrm{CA}$ & CTA \\
\hline a & 3 & 2 & 0.70 & 0.66 & 0.65 & 0.63 \\
\hline $\mathrm{b}$ & $3-4$ & 3 & 1.00 & 0.80 & 0.88 & 0.70 \\
\hline c & $3-4$ & $2-3$ & 1.10 & 0.82 & 0.90 & 0.73 \\
\hline$d$ & 3 & 2 & 0.69 & 0.64 & 0.62 & 0.60 \\
\hline e & $3-4$ & 3 & 1.32 & 1.00 & 1.21 & 0.93 \\
\hline$f$ & $3-4$ & 3 & 0.96 & 0.92 & 0.93 & 0.90 \\
\hline$g$ & $3-4$ & $2-3$ & 0.66 & 0.62 & 0.58 & 0.55 \\
\hline $\mathrm{h}$ & 3 & $2-3$ & 0.93 & 0.90 & 0.92 & 0.87 \\
\hline i & $3-4$ & 3 & 0.92 & 0.88 & 0.90 & 0.86 \\
\hline
\end{tabular}

Key: - Change in shade: 5 = Excellent, 4 = Very good, 3 = Good, 2 =Fair, 1 = Poor. 
TABLE 4: DYE WASH FASTNESS PROPERTIES ISO3 AND ISO4 GRAY SCALE RATING ON CELLULOSE ACETATE AND CELLULOSE TRIACETATE.

\begin{tabular}{|c|c|c|c|c|c|c|c|c|}
\hline \multirow{3}{*}{$\begin{array}{l}\text { Substrate } \\
\text { Dye }\end{array}$} & \multicolumn{4}{|c|}{ Cellulose acetate } & \multicolumn{4}{|c|}{ Cellulose Triacetate } \\
\hline & \multicolumn{2}{|c|}{ Change in shade } & \multicolumn{2}{|c|}{ Degree of staining } & \multicolumn{2}{|c|}{ Change in Shade } & \multicolumn{2}{|c|}{ Degree of staining } \\
\hline & ISO3 & ISO4 & ISO3 & ISO4 & ISO3 & ISO4 & ISO3 & ISO4 \\
\hline $\mathrm{a}$ & 4 & $3-4$ & 3 & 3 & $4-5$ & 4 & $2-3$ & $2-3$ \\
\hline$b$ & $3-4$ & 3 & 3 & $2-3$ & 4 & $3-4$ & $2-3$ & $2-3$ \\
\hline c & $3-4$ & 3 & 3 & 3 & 4 & $3-4$ & 3 & $2-3$ \\
\hline$d$ & $3-4$ & 3 & $3-4$ & 3 & 4 & $3-4$ & 3 & $2-3$ \\
\hline e & 4 & $3-4$ & 3 & $3-4$ & 4 & 4 & $2-3$ & $2-3$ \\
\hline$f$ & $3-4$ & 3 & 3 & $3-4$ & $3-4$ & 3 & $2-3$ & $2-3$ \\
\hline g & $3-4$ & 3 & $3-4$ & 3 & $3-4$ & 3 & 3 & 3 \\
\hline $\mathrm{h}$ & 4 & $3-4$ & 3 & 3 & 4 & $3-4$ & 3 & 3 \\
\hline $\mathrm{i}$ & 4 & $3-4$ & $3-4$ & 3 & 4 & $3-4$ & 3 & $2-3$ \\
\hline
\end{tabular}

Scale rating:-

Change in shade: -5 = Excellent, $4=$ Very Good, $3=$ Good, $2=$ Fair, $1=$ Poor .

Degree of staining of adjacent undyed material : $-5=$ No stain, $4=$ Very slight stain, $3=$ Appreciable stain, $2=$ Deep stain, $1=$ Completely stained

TABLE 5: DYE ADMIXTURE WASH FASTNESS PROPERTIES ISO3 AND ISO4 GRAY SCALE RATING ON CELLULOSE ACETATE AND CELLULOSE TRIACETE.

\begin{tabular}{|c|c|c|c|c|c|c|c|c|}
\hline \multirow{3}{*}{$\begin{array}{l}\text { Substrate } \\
\text { Dye Admixture } \\
1: 1 \text { ratio } \\
\end{array}$} & \multicolumn{4}{|c|}{ Cellulose Acetate } & \multicolumn{4}{|c|}{ Cellulose Triacetate } \\
\hline & \multicolumn{2}{|c|}{$\begin{array}{l}\text { Change } \\
\text { in shade }\end{array}$} & \multicolumn{2}{|c|}{$\begin{array}{c}\text { Degree } \\
\text { Of staining }\end{array}$} & \multicolumn{2}{|c|}{$\begin{array}{l}\text { Change in } \\
\text { Shade }\end{array}$} & \multicolumn{2}{|c|}{$\begin{array}{c}\text { Degree of } \\
\text { Staining } \\
\end{array}$} \\
\hline & ISO3 & ISO4 & ISO3 & ISO4 & ISO3 & ISO4 & ISO3 & ISO4 \\
\hline$a \& d$ & $3-4$ & 3 & $3-4$ & $3-4$ & $3-4$ & $3-4$ & 4 & 4 \\
\hline$b \& c$ & $3-4$ & 3 & $3-4$ & $3-4$ & $3-4$ & $3-4$ & 4 & 4 \\
\hline $\mathrm{h} \& \mathrm{i}$ & 3 & 3 & $3-4$ & $3-4$ & 4 & 4 & 4 & 4 \\
\hline$g \& h$ & $\mathrm{~S}$ & $\mathrm{~S}$ & S & S & S & S & S & S \\
\hline e \& g & $S$ & S & $S$ & $S$ & $S$ & $S$ & S & $S$ \\
\hline$c \& i$ & $\mathrm{~S}$ & S & $S$ & $\mathrm{~S}$ & $S$ & $S$ & $S$ & $S$ \\
\hline 1:3 ratio & ISO3 & ISO4 & ISO3 & ISO4 & ISO3 & ISO4 & ISO3 & ISO4 \\
\hline$a \& d$ & $3-4$ & 3 & $3-4$ & $3-4$ & 3 & 3 & 3 & $3-4$ \\
\hline$b \& c$ & $3-4$ & 3 & $3-4$ & $3-4$ & $3-4$ & $3-4$ & 4 & 4 \\
\hline $\mathrm{h} \& \mathrm{i}$ & 3 & $3-4$ & $3-4$ & 4 & 4 & $3-4$ & 4 & 4 \\
\hline$g \& h$ & $S$ & $S$ & $S$ & $S$ & $S$ & $S$ & $S$ & $S$ \\
\hline e \& g & $\mathrm{S}$ & $S$ & S & $\mathrm{S}$ & S & S & S & $S$ \\
\hline$c \& 1$ & S & S & $S$ & $\mathrm{~S}$ & $S$ & $S$ & $S$ & $S$ \\
\hline
\end{tabular}

$\mathrm{S}=$ skittering (Differential stain)

Scale rating:-

Change in shade: $-5=$ Excellent, $4=$ Very Good, $3=$ Good, $2=$ Fair, $1=$ Poor .

Degree of staining: -5 = No stain, 4 = Very slight stain, 3 = Appreciable stain, 2 = Deep stain, 1 = Completely stained. 
The apparent diffusion coefficient was higher in cellulose acetate than the triacetate. For instance "a" showed diffusion at $373 \mathrm{~K}$ to be 0.70 in $\mathrm{CA}$ and $0.66 \mathrm{CTA}$ at $353 \mathrm{~K}$, the diffusion coefficient of "a" was 0.65 in CA and 0.63 CTA. This could be due to configurational factors as above

Wash Fastness: The wash fastness properties using the ISO3 and ISO4 graduated procedure in all cases showed a reverse trend with fastness in triacetate generally better than acetate (Table 4). As an illustration "dye a" showed change in shade ratings of 4 and $3-4$ in CA compared to ratings of $4-5$ and 4 in CTA respectively using the two procedures. Also dye "b", "c" and "d" in triacetate showed ratings 4 which are better than the acetate in which the ratings are 3-4 for dye "b", "c" and "d". This again is attributed to high degree of molecular order that prevented dye molecules from diffusing out in cellulose triacetate comparable to the more amorphous cellulose acetate.

Application of some dyes such $\mathrm{a}, \mathrm{d}, \mathrm{g}, \mathrm{h}$ and $\mathrm{i}$ in cellulose acetate and triacetate exhibited pink coloured admixture and did not lead to skittering (Shore 1990). In comparison dyes g, h, e, c and i exhibited skittering. Similarly uniform shades of pink coloration were obtained when $b$ and $c$ were dyed in admixture (Table 5). The improved properties observed were demonstrated visually by elegance and brightness

It is concluded that synthesized azo dyes from 2- aminothiazole derivatives have shown better migration and diffusion in cellulose acetate compared with cellulose triacetate. The wash fastness properties however showed a reversal trend with cellulose acetate having better wash fastness than cellulose acetate. Skittering effects were observed for some dyes in admixture particularly dyes with appreciable difference in migration and diffusion.

These observations point to the fact that the degree of crystallinity is higher in cellulose triacetate. This arises from compact and ordered molecular configuration and also molecular differences. There is also an improved elegance and brightness of the fibre arising from dyes with similar dyeing rate and migration properties when applied in admixture such as dyes $a$ and $d, b$ and $c$ and $h$ and $i$.

\section{REFERENCES}

Arcoria, A, De Gorgi, R. M, Fatuzeo, F. \& Longo, L. M. 1993. Dyeing properties of Basic azo dye from 2 - aminothiadiazole Dyes and pigments.:21:67-74
Birds, C. L. \& Harris, C. J. 1957. Theory of colouration of Textiles Dyes Company Trust Soceities of Dyers and Colourist, Banford. $3^{\text {rd }}$ Edition..

Bello, K. A. Martins, C. M. \& Adamu, I. K. 1995. Synthesis and spectroscopic properties of azo dyes derived from 2-aminothiazole derivatives: Colourage Bombay:29-32.

Trotman, R. E. 1984. Dyeing and Chemical Technology of Textile Fibres. Charles Griffin.

Mark, F. H, Overberger F. D. \& Seaberg, T. G. 1992. Kirk Othmer Encyclopaedia of Chemical Technology, John Willey and Sons, NewYork

Mamuda, A.; Bello. K. A. \& Yakubu, M. K. 2002. Comparison of fixation characteristics of new acid fixing reactive dyes derived from 5,10 phenophosphazine ring with commercial reactive dyes on nylon 66 wool substrates; Journal of Scientific and Industrial research, 61:729733

Oyewale, A. O.; Bello, K. A. \& Adamu, K. I. 2003. Effect of acetylation and benzoylation on the electronic and dyeing properties of diazo disperse dyes derived from melamine. Nigerian Journal Scientific Research 4:61-67.

Preston, C. 1986. The dyeing of Cellulose Fibres Publication thrust, London. Standard methods for determination of fastness properties of textiles and leather, $4^{\text {th }}$ Edition. 1978. Soceity of dyers and colourists, Brandford.

Stevens, P. M. 1990. Polymer Chemistry - An Introduction. Oxford University Press, New York. 2nd Edition.

Shore, J. 1990. Colourants and Auxillaries, Organic Chemistry and application processes, Vol. 1. Colourants Society of Dyers and Colourists, UK 